\title{
Letter to the Editor: Factors Influencing a Medical Student's Decision to Pursue Surgery as a Career
}

\author{
Ahmed Soualhi $^{1}$ (D) Masud Awil $^{1} \cdot$ Haris Shoaib $^{1} \cdot$ Bilal Ahmad $^{1} \cdot$ Furhan Mukhtar $^{1}$
}

Published online: 2 January 2020

(C) Société Internationale de Chirurgie 2020

As medical students considering a career in surgery, we read with interest the study by Shelton et al. [1] that explored the effects of early exposure to surgery on medical students. Whilst a longitudinal surgical skills course such as that described in the study is welcome, we feel that more needs to be done to address the reduced interest among medical students in pursuing a career in surgery.

An important consideration that needs to be promoted to medical students when discussing surgery as a career option is the possibility of flexible training. In the UK, less than full-time training is available-under certain criteria-for surgical trainees who seek a more flexible training programme. Less than full-time training has become increasingly popular, with many taking advantage of the option to achieve their ambitions of training in surgery whilst maintaining a healthier work-life balance [2]. Whilst less than full-time training is not without its problems [3], we feel that it should be presented as an option to medical students during careers talks and discussions in medical schools. Boards and Royal Colleges in charge of surgical training and careers in surgery should also widely publicise and promote the availability of less than full-time training. This would be especially relevant for female medical students considering a career in surgery. It has been reported that women find pursuing a career in surgery incompatible with their other life goals, resulting in a noticeably lower number of women who decide to specialise in surgery [4]. It has also been shown that the inclusivity of a wider demographic of medical students and doctors, and the

Ahmed Soualhi

ahmed.soualhi@kcl.ac.uk

1 GKT School of Medical Education, King's College London, London, UK resulting diverse workforce, contributes to better patient care [5].

Healthcare systems in other countries should consider introducing and promoting a system such as less than fulltime training that would attract the best medical students to consider surgery, as well as reduce attrition from surgical training further down the line. Through this and other such interventions, shortages in the surgical workforce can be addressed by promoting consideration of a career in surgery for medical students.

\section{References}

1. Shelton J, Obregon M, Luo J et al (2019) Factors influencing a medical student's decision to pursue surgery as a career. World J Surg. https://doi.org/10.1007/s00268-019-05167-9

2. Harries RL, McGoldrick C, Mohan H et al (2015) Less than fulltime training in surgical specialities: consensus recommendations for flexible training by the association of surgeons in training. Int $\mathrm{J}$ Surg 23:S10-S14

3. Harries RL, Gokani VJ, Smitham P et al (2016) Less than full-time training in surgery: a cross-sectional study evaluating the accessibility and experiences of flexible training in the surgical trainee workforce. BMJ Open 6:e010136

4. Skinner H, Bhatti F (2019) Women in surgery. Bull R Coll Surg Engl 101:S12-S14

5. AAPCHO (2012) Fact sheet: the need for diversity in the health care workforce. http://www.aapcho.org/wp/wp-content/uploads/ 2012/11/NeedForDiversityHealthCareWorkforce.pdf. Accessed 27 Oct 2019

Publisher's Note Springer Nature remains neutral with regard to jurisdictional claims in published maps and institutional affiliations. 